\title{
Article \\ Synthesis of Ag Loaded ZnO/BiOCl with High Photocatalytic Performance for the Removal of Antibiotic Pollutants
}

\author{
Zhihao Zhang ${ }^{1}$, Amir Zada ${ }^{2}$, Nan Cui ${ }^{3}$, Naiwen Liu ${ }^{3}$, Minghui Liu $^{3}$, Yuzhuo Yang ${ }^{3}$, Delong Jiang ${ }^{1, *}$, \\ Jianhui Jiang ${ }^{4, *}$ and Shuyuan Liu ${ }^{5, *}$ \\ 1 Jilin Institute of Chemical Technology, Jilin 132022, China; zhangzh202107@163.com \\ 2 Department of Chemistry, Abdul Wali Khan University Mardan, Mardan 23200, Pakistan; \\ amirzada@awkum.edu.pk \\ 3 Institute of Catalysis for Energy and Environment, College of Chemistry and Chemical Engineering, \\ Shenyang Normal University, Shenyang 110034, China; 15842743380@163.com (N.C.); \\ naiwenliu2021@163.com (N.L.); Imh15241637597@163.com (M.L.); yangyuzhuo202107@163.com (Y.Y.) \\ 4 College of Life Science, Tarim University, Alar 843300, China \\ 5 Department of Pharmacology, Shenyang Medical College, Shenyang 110032, China \\ * Correspondence: Isy_19870110@126.com (D.J.); xjjjh78@163.com (J.J.); liushuyuan@symc.edu.cn (S.L.)
}

check for updates

Citation: Zhang, Z.; Zada, A.; Cui, N.; Liu, N.; Liu, M.; Yang, Y.; Jiang, D.; Jiang, J.; Liu, S. Synthesis of Ag Loaded $\mathrm{ZnO} / \mathrm{BiOCl}$ with High Photocatalytic Performance for the Removal of Antibiotic Pollutants.

Crystals 2021, 11, 981.

https://doi.org/10.3390/

cryst11080981

Academic Editor: Roberto Comparelli

Received: 1 July 2021

Accepted: 10 August 2021

Published: 18 August 2021

Publisher's Note: MDPI stays neutral with regard to jurisdictional claims in published maps and institutional affiliations.

Copyright: (c) 2021 by the authors. Licensee MDPI, Basel, Switzerland. This article is an open access article distributed under the terms and conditions of the Creative Commons Attribution (CC BY) license (https:// creativecommons.org/licenses/by/ $4.0 /)$.

\begin{abstract}
Ag@ZnO/BiOCl composites were successfully prepared by in situ precipitation and hydrothermal synthesis and used for the photocatalytic degradation of tetracycline hydrochloride antibiotics. An enhanced photodegradation efficiency was detected after loading Ag nanoparticles, which is attributed to the surface plasmon resonance effect. The optimized sample containing $4 \% \mathrm{Ag}$ showed $80.4 \%$ degradation efficiency in $80 \mathrm{~min}$, which is 2.1 and 1.9 times higher than those of $\mathrm{ZnO}$ and $\mathrm{ZnO} / \mathrm{BiOCl}$, respectively. The major degrading species involved in the photocatalytic process were detected to be super oxide anions and holes. Based on the obtained results, a possible charge transfer and degradation mechanism has been proposed. This study shows that Ag@ZnO/BiOCl catalyst has a good potential for photodegradation of organic pollutants in water.
\end{abstract}

Keywords: Ag@ZnO/BiOCl; photocatalyst; degradation; tetracycline hydrochloride; simulated solar light

\section{Introduction}

Tetracycline hydrochloride $(\mathrm{TC}-\mathrm{HCl})$ is a widely used antibiotic, and its production is second place in the world [1]. TC- $\mathrm{HCl}$ is discharged into the surrounding water environment through human and animal metabolism and pharmaceutical companies and enters the human body through the food chain [2]. The accumulation of $\mathrm{TC}-\mathrm{HCl}$ and other antibiotics results in drug resistance pathogenic bacteria, and therefore has vast effects on human health and aquatic life [3]. In order to prevent their large scale accumulation in water, photocatalytic degradation with the help of photocatalysts such as $\mathrm{TiO}_{2}, \mathrm{ZnO}$, $\mathrm{SnO}_{2}, \mathrm{~g}_{-} \mathrm{C}_{3} \mathrm{~N}_{4}$, etc., has been carried out in-depth [4-14]. However, most of the photocatalysts are only active under ultraviolet, which comprises a limited portion of the solar spectrum [15-24]. Therefore, it is necessary to find photocatalysts with good visible light absorption performance.

$\mathrm{ZnO}$ has the advantages of high electron mobility, non-toxicity, and high photosensitivity, with excellent activity for the photocatalytic degradation of organic pollutants in wastewater [25-27]. However, its wide band gap results in its poor light response in the visible range. In addition, the high recombination rate of photogenerated electrons and holes further retard its activity. Therefore, its combination with other semiconductors is highly appreciated to overcome these deficiencies. As a n-type semiconductor, its combination with p-type semiconductors such as $\mathrm{BiOCl}$ is an effective strategy to improve the photocatalytic activity by charge transfer and separation from $\mathrm{BiOCl}$ to $\mathrm{ZnO}$ [28]. 
Noble metals such as Au and Ag can be used as driving agents for photocatalytic performance when deposited on a photocatalyst surface to improve visible light absorption through their surface plasmon resonance effects [29-32]. The introduction of these metals not only enhances visible light absorption, but they also play a very important role in charge separation and surface catalysis due to their metallic nature. Particularly, the Ag nanoparticles formed by reduction of $\mathrm{Ag}^{+}$ions by oxygen vacancy are very attractive, as $\mathrm{Ag}$ is relatively chief compare to $\mathrm{Au}$ [33]. With the quenching of oxygen vacancy and plasma effect at the close interface between $\mathrm{Ag}$ and the semiconductor composites, $\mathrm{Ag}$ can be more efficient in the removal of organic pollutants in water system under visible light irradiation. Many experiments show that Ag nanoparticles can promote the photocatalytic reactions. For example, Christopher et al. prepared $\mathrm{Ag}$ and $\mathrm{TiO}_{2}$ composite photocatalyst, which showed higher photo-responsive activity than pure $\mathrm{TiO}_{2}$ in the photodegradation process of methylene blue [34]. The Ag modified $\mathrm{ZnO}$ nanorods were prepared by Ren et al., and the photocatalytic performance of $\mathrm{Ag} / \mathrm{ZnO}$ for the degradation of methyl blue was greatly improved compared to pure $\mathrm{ZnO}$ nanorods [35]. Rupa et al. investigated the photocatalytic degradation of active yellow- 17 by $\mathrm{Ag}-\mathrm{TiO}_{2}$ under light irradiation and found that $\mathrm{TiO}_{2}$ deposited by Ag can promote the degradation process [36].

In this work, a series of $\mathrm{ZnO} / \mathrm{BiOCl}$ composite photocatalysts were successfully prepared by hydrothermal synthesis and in situ coprecipitation and noble metal Ag was loaded on the surface of the $\mathrm{ZnO} / \mathrm{BiOCl}$ to get $\mathrm{Ag} @ \mathrm{ZnO} / \mathrm{BiOCl}$ composites. The as-prepared samples showed enhanced photocatalytic degradation activity for TC- $\mathrm{HCl}$ under the simulated solar light due to extended visible light absorption and improved charge separation. Based on the obtained results, a schematic showing charge transfer and separation has been proposed.

\section{Experimental Section}

\subsection{Synthesis of $\mathrm{ZnO}$ Nanoparticles}

For the preparation of $\mathrm{ZnO}$ nanoparticles, $1.317 \mathrm{~g} \mathrm{Zn}\left(\mathrm{CH}_{3} \mathrm{COO}\right)_{2} \cdot 2 \mathrm{H}_{2} \mathrm{O}(0.006 \mathrm{~mol})$ were dissolved in $20 \mathrm{~mL}$ ultrapure water in a beaker. About $0.6 \mathrm{~g} \mathrm{NaOH}(0.015 \mathrm{~mol})$ were also dissolved in $20 \mathrm{~mL}$ water and added dropwise to $\mathrm{Zn}\left(\mathrm{CH}_{3} \mathrm{COO}\right)_{2} \cdot 2 \mathrm{H}_{2} \mathrm{O}$ solution under constant stirring. The resultant solution was taken in $50 \mathrm{~mL}$ autoclave and heated at $140{ }^{\circ} \mathrm{C}$ for $12 \mathrm{~h}$ in an oven. The obtained precipitate was filtered, washed with deionized water and then dried at $80{ }^{\circ} \mathrm{C}$ in an oven. The dried sample was calcined at $450{ }^{\circ} \mathrm{C}$ for $60 \mathrm{~min}$ to get $\mathrm{ZnO}$ nanoparticles.

\subsection{Synthesis of $\mathrm{ZnO} / \mathrm{BiOCl}$ Nanocomposites}

For the synthesis of $\mathrm{ZnO} / \mathrm{BiOCl}$ composite, $1.616 \mathrm{~g} \mathrm{Bi}\left(\mathrm{NO}_{3}\right)_{3} \cdot 5 \mathrm{H}_{2} \mathrm{O}(0.00333 \mathrm{~mol})$ and $0.252 \mathrm{~g} \mathrm{KCl}(0.00338)$ were dissolved in deionized water and mixed with $0.405 \mathrm{~g} \mathrm{ZnO}$ nanoparticles. The suspension was stirred for $30 \mathrm{~min}$ and transferred to 50 autoclave. The autoclave was heated at $100^{\circ} \mathrm{C}$ for $12 \mathrm{~h}$. The obtained precipitate was filtered, washed with deionized water and then dried at $80^{\circ} \mathrm{C}$ in an oven to get $\mathrm{ZnO} / \mathrm{BiOCl}$ nanocomposite.

\subsection{Synthesis of $\mathrm{Ag}$ Loaded $\mathrm{ZnO} / \mathrm{BiOCl}$ Nanocomposites}

For the preparation of $\mathrm{Ag}$ loaded $\mathrm{ZnO} / \mathrm{BiOCl}$ nanocomposites, $0.2 \mathrm{~g} \mathrm{ZnO} / \mathrm{BiOCl}$ were dispersed in $60 \mathrm{~mL}$ ultrapure water under ultrasonication for $20 \mathrm{~min}$. Different volumes of $\mathrm{AgNO}_{3}$ solution $(0.1 \mathrm{M}, 1-7 \mathrm{~mL})$ were added to the above solution dropwise and stirred in dark for $30 \mathrm{~min}$. The well dispersed mixture was irradiated under a xenon light source for $1 \mathrm{~h}$. The mixture centrifuged $(7000 \mathrm{r} / \mathrm{min}, 10 \mathrm{~min}$ ) after standing, and the precipitates were placed in a vacuum drying oven at $60^{\circ} \mathrm{C}$ for $24 \mathrm{~h}$ to get gray black samples. According to the volume of the added silver nitrate, the theoretical Ag content is calculated to be 5, 10, $15,20,25,30$ and $35 \%$. These samples were represented by $\mathrm{X} \%-\mathrm{Ag} @ \mathrm{ZnO} / \mathrm{BiOCl}$, where $\mathrm{X} \%$ shows the percent amount of $\mathrm{Ag}$ in the nanocomposites. 


\subsection{Characterization}

The Bruker D8 Advance X-ray diffractometer (XRD, Cu k $\alpha, \lambda=1.54056 \AA$ ) was used to study the crystal phase of the samples. X-ray photoelectron spectroscopy (XPS) was measured on PHIQ1600 XPS (US) instrument. High resolution transmission electron microscopy (HRTEM) was carried out with Japanese JEOL-JEM-2100F electron microscope. The UV-Vis absorption spectra were collected on the Shimadzu UV3100 (Kyoto, Japan) spectrophotometer using $\mathrm{BaSO}_{4}$ as reference. The photoluminescence (PL) spectra of $\mathrm{ZnO}$ and nanocomposite samples were studied on a Varian-Cary solar eclipse spectrometer with an excitation wavelength of $325 \mathrm{~nm}$.

\subsection{Photocatalytic Activity Measurements}

The photocatalytic performance of the $4 \%-\mathrm{Ag} @ \mathrm{ZnO} / \mathrm{BiOCl}$ composites was tested by photocatalytic degradation of $\mathrm{TC}-\mathrm{HCl}$ experiments using simulated solar light. As such, 32 mg Ag@ZnO/BiOCl catalysts were dispersed with $50 \mathrm{~mL} \mathrm{TC}-\mathrm{HCl}(20 \mathrm{mg} / \mathrm{L})$ solution. The mixture was stirred in dark for $30 \mathrm{~min}$ to achieve adsorption of some amount of pollutant. About $5 \mathrm{~mL}$ solution was taken from it with the help of a disposable syringe, and the rest of the solution was irradiated under simulated solar light for $2 \mathrm{~h}$, keeping the temperature constant at $25^{\circ} \mathrm{C}$. About $5 \mathrm{~mL}$ solution was drawn after each $20 \mathrm{~min}$ interval and the contents were centrifuged to remove the suspended particles. The sample was checked with UV-Vis spectrophotometer at $357 \mathrm{~nm}$ to measure the degradation rate and efficiency of Ag@ZnO/BiOCl. Furthermore, the effects of catalyst dosage, pH value and impurity ions on degradation were investigated.

\section{Results and Discussion}

\subsection{XRD Analysis}

The XRD patterns of $\mathrm{ZnO}, \mathrm{BiOCl}$ and $\mathrm{Ag} @ \mathrm{ZnO} / \mathrm{BiOCl}$ catalysts with different loading ratios are shown in Figure 1. The $\mathrm{ZnO} / \mathrm{BiOCl}$ composites containing different $\mathrm{Ag}$ ratios have the same diffraction peaks, with the strong diffraction peak angles at 31.78, 34.42, $36.26,47.54,56.58,62.84$ and $67.94^{\circ}$ corresponding, respectively, to the crystal faces (100), (002), (101), (102), (110), (103) and (112) of ZnO (PDF card 36-1451). The diffraction peaks at $12.05,25.87,32.56,33.4740 .84,46.78,49.82,54.12$ and $58.74^{\circ}$ correspond, respectively, to (001), (101), (110), (102), (112), (200), (113), (211) and (212) facets of BiOCl according to the standard PDF card (06-0249). The intensity of the diffraction peaks of the BiOCl at (101) and $\mathrm{ZnO}$ at (101) faces are obvious, which indicate that the $\mathrm{Ag} @ \mathrm{ZnO} / \mathrm{BiOCl}$ composite is successfully prepared. With the increase of the loading amount, the (101) diffraction peak of $\mathrm{ZnO}$ decreases gradually, which is due the $\mathrm{XRD}$ diffraction intensity of $\mathrm{BiOCl}$ is relatively high. From the XRD data, there is no other impurity diffraction peak, indicating that the purity of the sample is high. 


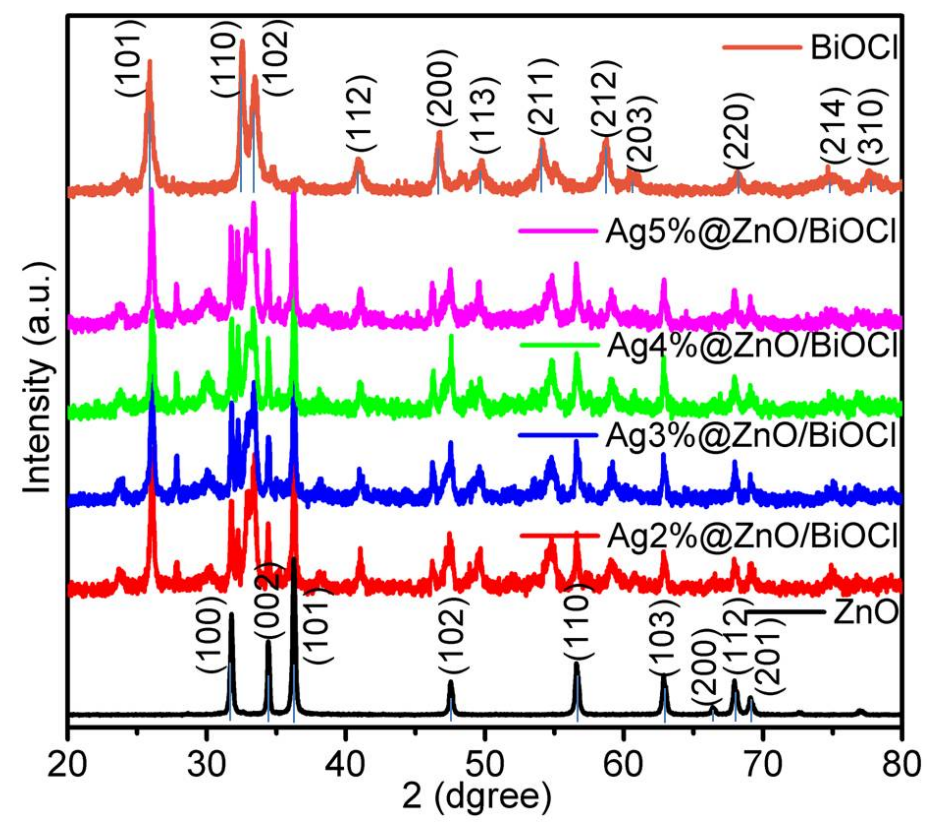

Figure 1. XRD patterns of $\mathrm{ZnO}$ and $\mathrm{X} \%-\mathrm{Ag} @ \mathrm{ZnO} / \mathrm{BiOCl}$ samples.

\subsection{Morphology Analysis}

The morphology of the synthesized composites was studied by TEM measurements. It can be seen from Figure 2 that the two materials grow in two-dimensional layered structure, showing good structural lattice edge and excellent crystallinity of the prepared materials. $\mathrm{ZnO}$ is rod-shaped with a lattice spacing of $0.247 \mathrm{~nm}$, corresponding to the (101) crystal surface of $\mathrm{ZnO}$. BiOCl also shows a trend of longitudinal growth with a rod-shaped structure having lattice spacing of $0.275 \mathrm{~nm}$ with the (110) crystal facet. This indicates the successful construction of heterojunction between $\mathrm{ZnO}$ and $\mathrm{BiOCl}$, which is very important for electrons transfer and conduction. Ag metal is present in the form of particles of $20 \mathrm{~nm}$ size. After Ag deposition, the smooth surface becomes rough, which is more conducive and provide large number of active sites. Additionally, according to SEM and corresponding elemental mapping images conducted for $4 \%-\mathrm{Ag} @ \mathrm{ZnO} / \mathrm{BiOCl}$ catalyst (Figure 3), it is confirmed the presence of $\mathrm{Zn}, \mathrm{O}, \mathrm{Bi}, \mathrm{Cl}$ and $\mathrm{Ag}$ elements in the composite, wherein these elements are distributed evenly.
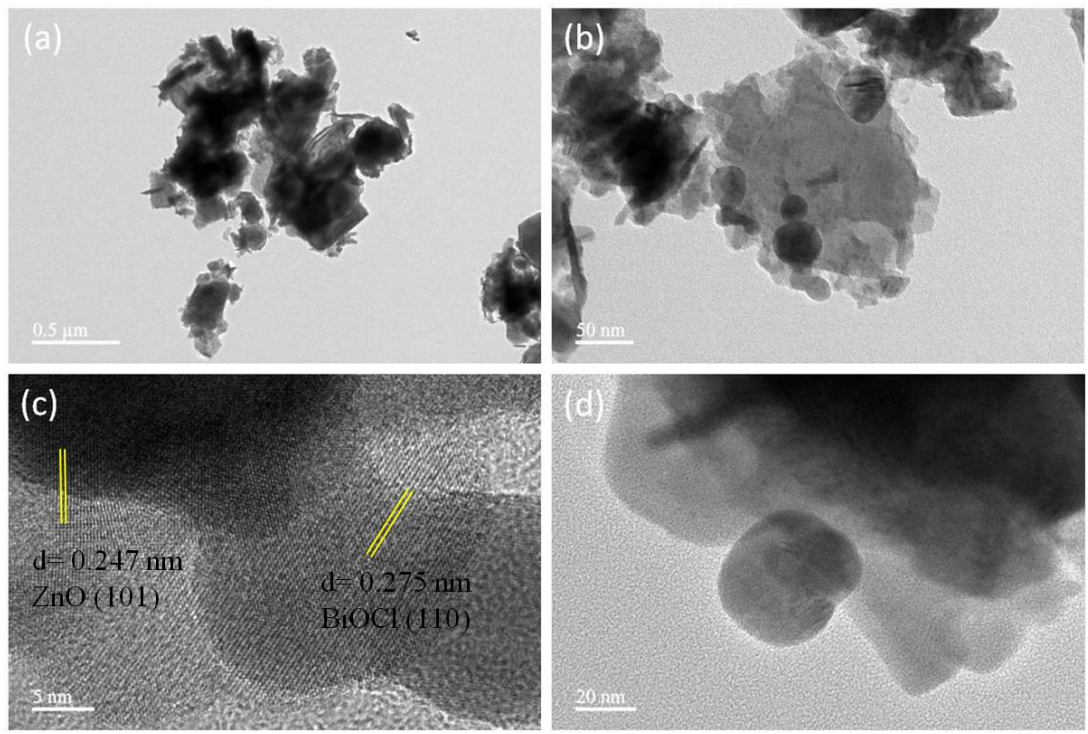

Figure 2. (a-d)TEM images of 4\%-Ag@ZnO/BiOCl catalyst. 

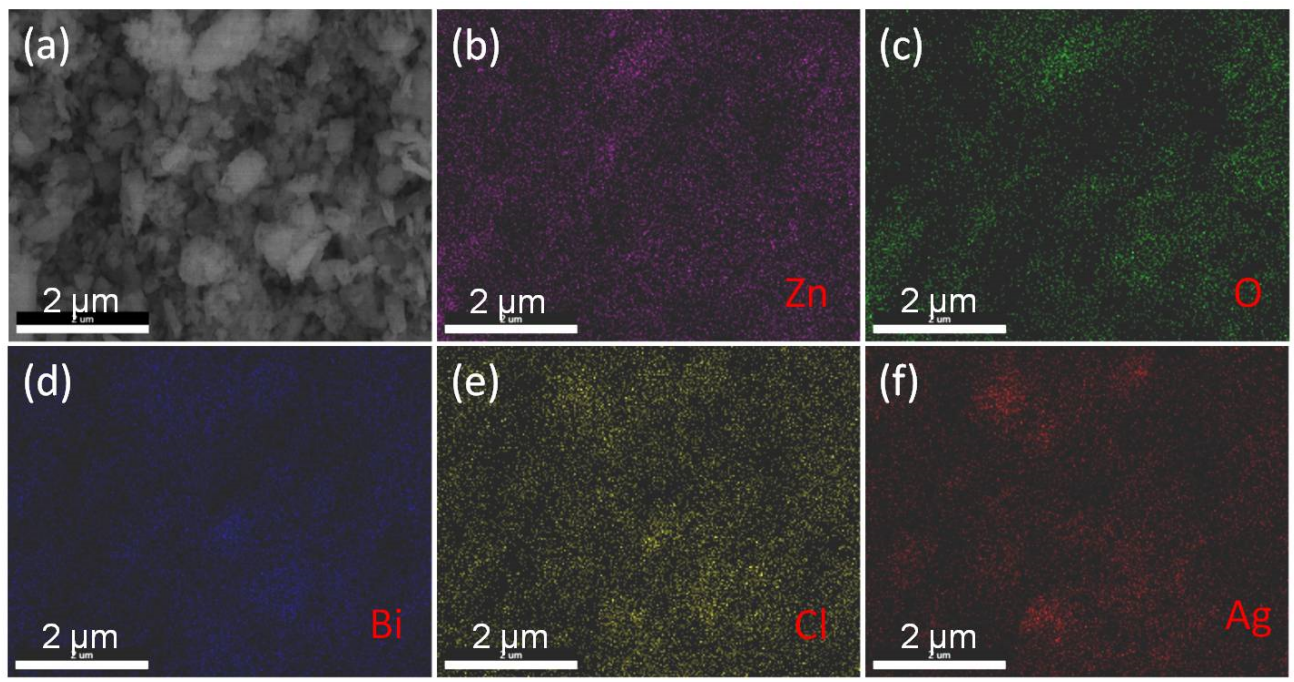

Figure 3. SEM image and the corresponding elemental mapping images of $4 \%-\mathrm{Ag} @ \mathrm{ZnO} / \mathrm{BiOCl}$ catalyst (a-f).

\subsection{XPS Analysis}

Figure 4 shows the XPS energy spectra of $4 \%-\mathrm{Ag} @ \mathrm{ZnO} / \mathrm{BiOCl}$. Obviously, there are $\mathrm{Zn}, \mathrm{O}, \mathrm{Ag}, \mathrm{Bi}, \mathrm{Cl}$ and $\mathrm{C}$ elements in the energy spectra showing the presence of these elements in 4\%-Ag@ZnO/BiOCl, while the C peak mainly comes from the XPS instrument itself (Figure 4a). This indicates high purity of $\mathrm{Ag}$ loaded $\mathrm{ZnO} / \mathrm{BiOCl}$ and successful construction of heterojunction between $\mathrm{ZnO}$ and $\mathrm{BiOCl}$, which is consistent with the TEM results. The XPS binding energies of $\mathrm{Zn} 2 \mathrm{p}$ in Figure $4 \mathrm{~b}$ are located at 1044.8 and $1021.5 \mathrm{eV}$ and correspond to the binding energy of $Z n 2 p_{1 / 2}$ and $Z n 2 p_{3 / 2}$ orbitals, respectively [37]. The biding energy peaks of Bi $4 \mathrm{f}$ in Figure $4 \mathrm{c}$ are deconvoluted into 164.2 and $159.1 \mathrm{eV}$ which, respectively, correspond to $\mathrm{Bi}_{4} \mathrm{f}_{5 / 2}$ and $\mathrm{Bi}_{4} \mathrm{f}_{7 / 2}$. These energy peaks shows +3 valence state of $\mathrm{Bi}$ in $\mathrm{ZnO} / \mathrm{BiOCl}$ composite [38]. The XPS spectrum of $\mathrm{Cl} 2 \mathrm{p}$ given in Figure $4 \mathrm{~d}$ is composed of two strong peaks with binding energy at 199.8 and $198.3 \mathrm{eV}$ and, respectively, corresponded to $\mathrm{Cl}_{2} \mathrm{p}_{1 / 2}$ and $\mathrm{Cl} 2 \mathrm{p}_{3 / 2}$ orbitals of $\mathrm{Cl}^{-}$. In addition, two asymmetric peaks in Figure 4e are the characteristic peaks of O1s, indicating that there are two different binding states of oxygen in the catalyst. The first peak is located at $531.5 \mathrm{eV}$, corresponding to $\mathrm{Zn}-\mathrm{O}$ bond [37], while the $530.1 \mathrm{eV}$ binding energy in the second peak corresponds to $\mathrm{Bi}-\mathrm{O}$ bond in $\mathrm{BiOCl}$ layered structure. The high resolution $\mathrm{Ag}$ $3 \mathrm{~d}$ spectrogram shows $\mathrm{Ag} 3 \mathrm{~d}_{5 / 2}$ and $\mathrm{Ag} 3 \mathrm{~d}_{3 / 2}$ orbitals, which correspond to $\mathrm{Ag}^{+}$and $\mathrm{Ag}^{0}$, respectively (Figure $4 \mathrm{f}$ ), indicate that $\mathrm{Ag}^{+}$has been successfully reduced to $\mathrm{Ag}^{0}$.

\subsection{UV-Vis DRS Analysis}

In order to evaluate the light absorption properties of the samples, UV-Vis diffuse reflectance spectra were measured. Figure 5 shows that the material has obvious absorption in the near ultraviolet range. For $\mathrm{ZnO}$, there is a typical absorption in the range of 200-400 $\mathrm{nm}$, while the maximum absorption peak intensity of $\mathrm{ZnO} / \mathrm{BiOCl}$ is lower than $\mathrm{ZnO}$. However, the visible light absorption intensity of $\mathrm{ZnO} / \mathrm{BiOCl}$ is slightly higher than $\mathrm{ZnO}$. The light absorption edges of $\mathrm{Ag} @ \mathrm{ZnO} / \mathrm{BiOCl}$ samples are almost the same in the ultraviolet region, but different in the visible region of 400-800 nm. Compare with pure $\mathrm{ZnO}$, the $\mathrm{Ag} @ \mathrm{ZnO} / \mathrm{BiOCl}$ composites show strong light absorption performance in the long wavelength range, and the absorption spectrum of the composite shows absorption in the range of 200-800 nm, which enhances the intrinsic absorption characteristics of $\mathrm{ZnO}$ [39]. This shows that Ag loading significantly increases the light absorption capacity of $\mathrm{ZnO} / \mathrm{BiOCl}$ for extended photocatalysis. 

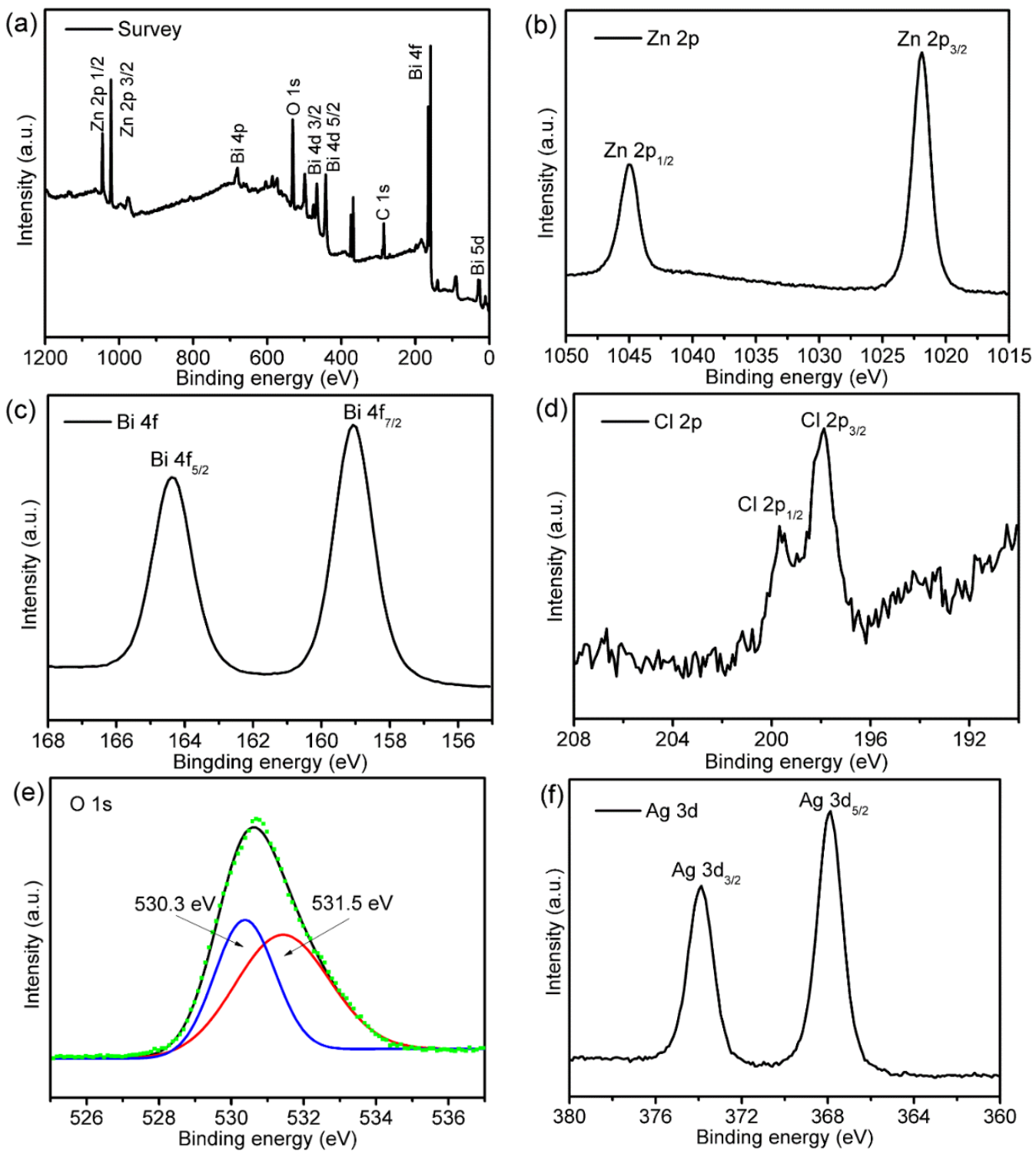

Figure 4. XPS survey spectra of 4\%-Ag@ZnO/BiOCl (a), Zn 2p (b), Bi 4f (c), Cl 2p (d), O 1s (e) and Ag 3d (f).

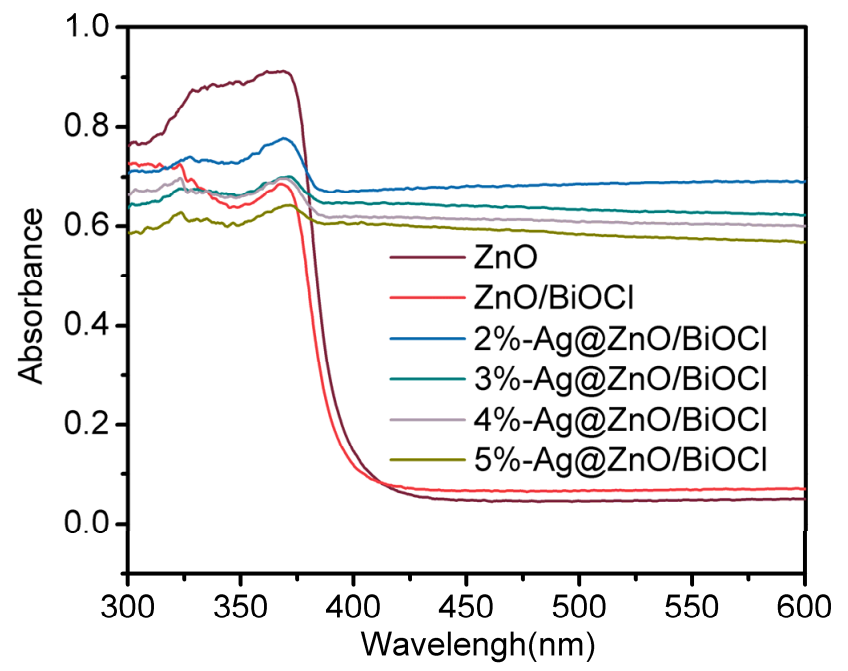

Figure 5. DRS spectrum of pure $\mathrm{ZnO}$ and $\mathrm{Ag@ZnO/BiOCl} \mathrm{samples.}$ 


\subsection{PL Analysis}

The photoluminescence (PL) spectra provide information about the separation and transportation of photogenerated carriers. Therefore, PL spectra of the samples were measured at $357 \mathrm{~nm}$ excitation wavelength, and the results are shown in Figure 6. There is a strong fluorescence emission peak at $450 \mathrm{~nm}$ for all the three samples. The photoelectric properties of $\mathrm{ZnO}$ have obvious changes after heterojunction formation with $\mathrm{BiOCl}$ and loading $\mathrm{Ag}$ nanoparticles. The order of the spectral intensity from strong to weak is: $\mathrm{ZnO}>\mathrm{ZnO} / \mathrm{BiOCl}>4 \%$-Ag@ZnO/BiOCl, which shows that $4 \%-\mathrm{Ag} @ \mathrm{ZnO} / \mathrm{BiOCl}$ has the largest fluorescence quenching, the most inhibition of electron-hole pair recombination, and the highest efficiency of photogenerated carrier separation [40]. The electron capturing property of Ag nanoparticles results in the effective transport and migration of excited electrons resulting in the increased separation of photogenerated electron-hole pairs, which lays a certain foundation for the active radicals needed in the subsequent reactions. Under simulated solar light irradiation, the excitation of Ag inducts excited electrons to the conduction band of $\mathrm{ZnO}$, which provides other ways for photogenerated charge transfer to suppress the fluorescence quenching of $\mathrm{ZnO}$ and the recombination of photogenerated electron-hole pairs.

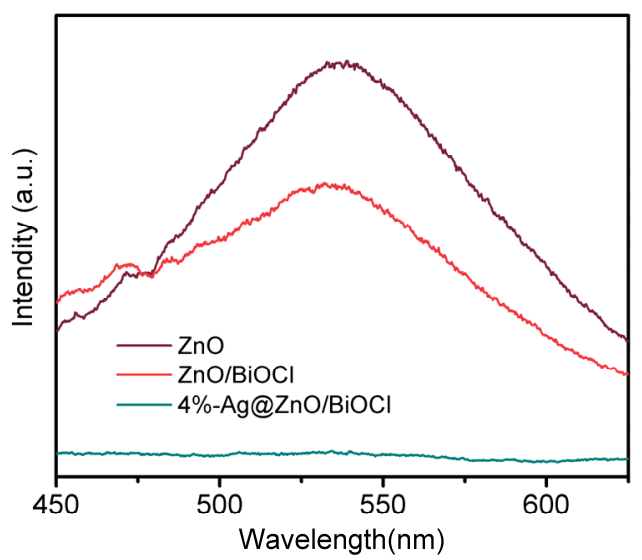

Figure 6. $\mathrm{PL}$ spectrum of pure $\mathrm{ZnO}, \mathrm{ZnO} / \mathrm{BiOCl}$ and 4\%-Ag@ZnO/BiOCl samples.

\section{Photocatalytic Activity}

\subsection{Photocatalytic Activity of Ag@ZnO/BiOCl}

Figure 7 shows the time-dependent concentration of TC-HCl degraded by Ag@ZnO/BiOCl nanocomposites with different amounts of Ag nanoparticles under simulated solar light. The $\mathrm{pH}$ value of the reaction solution is 8 . In the reaction process, the temperature is $25{ }^{\circ} \mathrm{C}$ and dark reaction time is $30 \mathrm{~min}$, taking samples every $20 \mathrm{~min}$. With the increase of Ag loading, the catalytic activity of $\mathrm{Ag} @ \mathrm{ZnO} / \mathrm{BiOCl}$ increases first and then decreases. The photocatalytic activity of $\mathrm{ZnO}$ is low, and the degradation rate is $38.5 \%$ in $80 \mathrm{~min}$. The degradation efficiency of $\mathrm{ZnO} / \mathrm{BiOCl}$ is slightly higher, reaching $42.7 \%$. Interestingly, the activities of all $\mathrm{Ag}$ loaded samples are higher than $\mathrm{ZnO} / \mathrm{BiOCl}$, and the degradation activity of $4 \% \mathrm{Ag}$ nanocomposite is the highest with $80.4 \%$ removal efficiency. The kinetic curves of the photodegradation of $\mathrm{TC}-\mathrm{HCl}$ agree with the quasi-first order kinetics. The $\mathrm{k}$ value of $4 \%-\mathrm{Ag} @ \mathrm{ZnO} / \mathrm{BiOCl}$ is the largest, which is three times more than that of $\mathrm{ZnO}$. These improved photoactivities of Ag loaded samples are attributed to more visible light absorption and enhanced charge separation due to surface plasmon resonance and electron trapping ability of $\mathrm{Ag}$ and improved surface catalysis due to metallic Ag. However, further increase in the amount of Ag decreases the degradation activity, which may be attributed to the aggregation of Ag nanoparticles at high concentrations. Thus, the introduction of noble metals is a feasible strategy to improve the photocatalytic efficiency of large band gap semiconductors. 

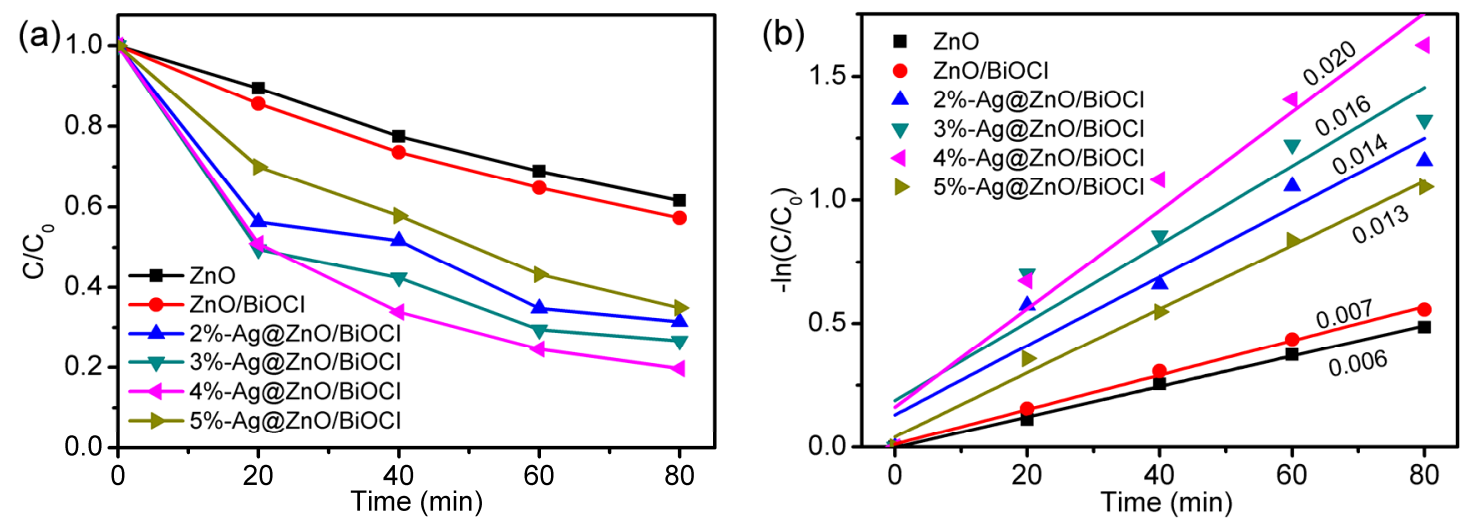

Figure 7. Photocatalytic degradation (a) and rate curve (b) of $\mathrm{TC}-\mathrm{HCl}$ by $\mathrm{ZnO}, \mathrm{ZnO} / \mathrm{BiOCl}$ and $\mathrm{Ag} @ \mathrm{ZnO} / \mathrm{BiOCl}$.

\subsection{Effect of Catalyst Amount}

The amount of photocatalyst has a great influence on the overall photocatalytic efficiency. Figure 8 shows the degradation curve of TC- $\mathrm{HCl}(20 \mathrm{mg} / \mathrm{L})$ in the presence of different dosages of the optimized photocatalyst under simulated solar light. When the amount of the photocatalyst is increased from 20 to $32 \mathrm{mg}$ per $50 \mathrm{~mL}$ of the pollutant solution, the degradation efficiency is increased from 50 to $82.6 \%$. This increase in the photoactivity is attributed to the adsorption of more pollutant particles available for the degradation under high amount of photocatalyst. However, when the amount of the photocatalyst is further increased to $40 \mathrm{mg}$, the photocatalytic efficiency is decreased to $70.1 \%$. This decrease in photocatalytic activity is attributed to the turbidity of the solution resulting in poor light transmittance at too much high concentration of the photocatalyst. Another reason is the aggregation of the particles of the photocatalysts at high concentration, which reduce the specific surface and results in lower activity. Thus, the optimum amount of photocatalyst in this experiment is $32 \mathrm{mg}$ per $50 \mathrm{~mL}$ of pollutant.

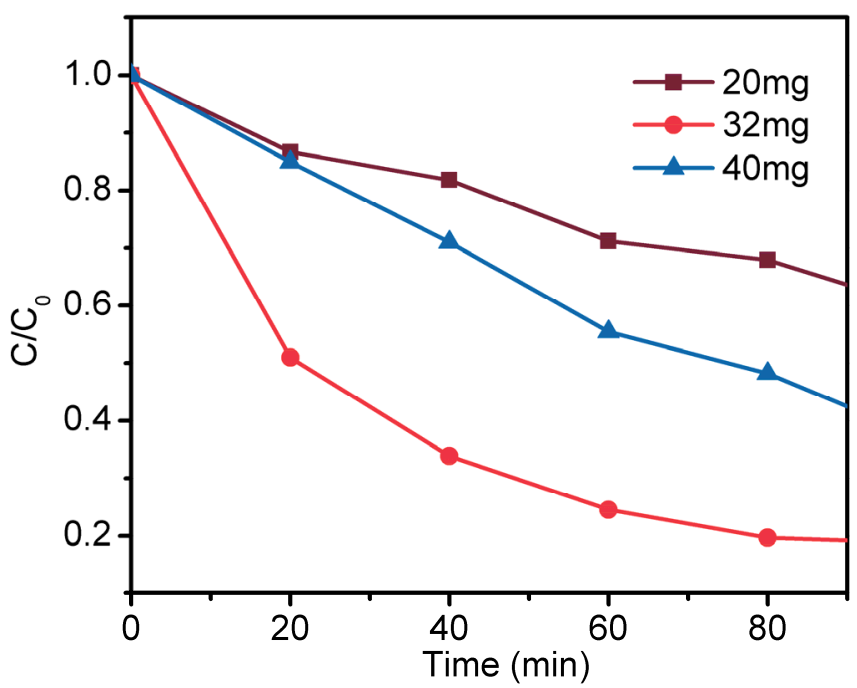

Figure 8. Photocatalytic degradation of TC- $\mathrm{HCl}$ by 4\%-Ag@ZnO/BiOCl dosage.

\subsection{Effect of Impurity Ions}

The photodegradation efficiency of $\mathrm{TC}-\mathrm{HCl}$ pollutants is examined with adding different impurity anions such as $\mathrm{Cl}^{-}, \mathrm{SO}_{4}{ }^{2-}, \mathrm{CO}_{3}{ }^{2-}, \mathrm{PO}_{4}{ }^{3-}$ and $\mathrm{NO}_{3}{ }^{-}$(Figure 9). The photoactivities are a little decreased after adding all these anions than that the photocatalytic activity of 4\%-Ag@ZnO/BiOCl without adding of anions. The different photocatalytic performance is due to the different tendencies of the anions to be oxidized by the photo- 
generated reactive oxygen species. These anions consume some of reactive oxygen species to prevent the decomposition of $\mathrm{TC}-\mathrm{HCl}$ pollutants.

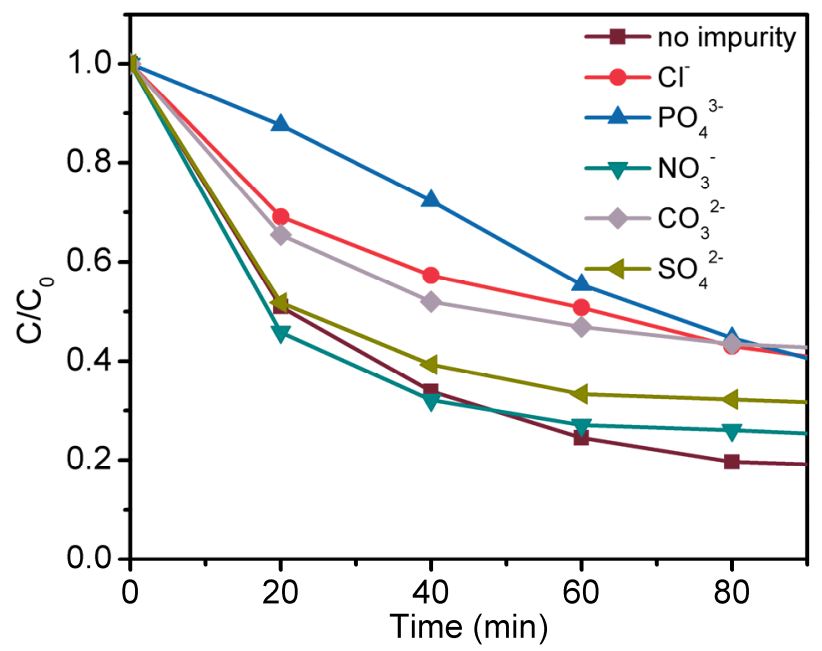

Figure 9. Photodegradation of $\mathrm{TC}-\mathrm{HCl}$ by $4 \%-\mathrm{Ag} @ \mathrm{ZnO} / \mathrm{BiOCl}$ under different impurity ions.

\subsection{Active Species}

During photocatalysis, different free radicals are generated when the excited electrons and holes are captured by water and other substances in aqueous solution. These free radicals are highly reactive and take part in the oxidation of the pollutants. It is very important to find out the major oxidizing radical involved in the degradation of TC-HCl. For this purpose, the active oxygen species are examined by free radical capturing experiments, as shown in Figure 10. Ascorbic acid, triethanolamine, and iso-propyl alcohol are used as sacrificial agents for ${ }^{\bullet} \mathrm{O}_{2}{ }^{-}, \mathrm{h}^{+}$and ${ }^{\bullet} \mathrm{OH}$, respectively. When ascorbic acid or triethanolamine is added to the reaction solution, the photocatalytic activity of $4 \%-\mathrm{Ag} @ \mathrm{ZnO} / \mathrm{BiOCl}$ is dramatically decreased. This indicates that ${ }^{\bullet} \mathrm{O}_{2}{ }^{-}$and $\mathrm{h}^{+}$play important roles in the photodegradation of TC- $\mathrm{HCl}$. When iso-propyl alcohol is added into the reaction solution, the effect on the photocatalytic degradation is not obvious, which indicates that ${ }^{\bullet} \mathrm{OH}$ is not the main species affecting the photocatalytic performance. Thus, the main active oxygen species affecting the photocatalytic activity are $\mathrm{h}^{+}$and ${ }^{\bullet} \mathrm{O}_{2}{ }^{-}$.

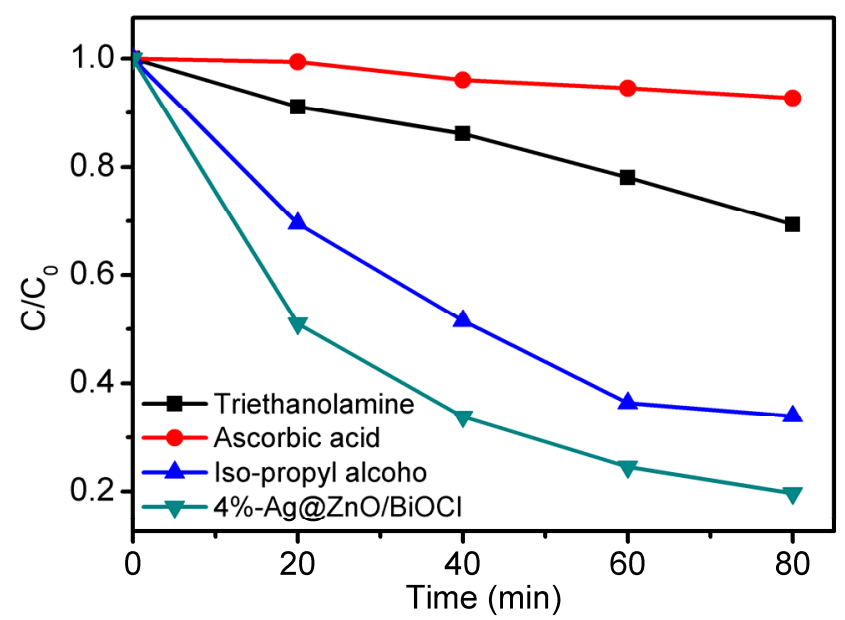

Figure 10. Photodegradation of TC- $\mathrm{HCl}$ by 4\%-Ag@ZnO/BiOCl under different trapping agents.

\subsection{Photocatalytic Mechanism}

A schematic has been proposed indicating the charge separation and transfer in $4 \%-\mathrm{Ag} @ \mathrm{ZnO} / \mathrm{BiOCl}$ and possible photocatalytic degradation mechanism of TC- $\mathrm{HCl}$ as 
shown in Figure 11. Before heterojunction construction, the Fermi levels of n-type $\mathrm{ZnO}$ are closed to its conduction band while the Fermi level of p-type BiOCl are closed to its valence band. There is a great difference between the Fermi level potentials of the two materials. When the two materials are compounded to form heterojunction, the Fermi levels are stabilized at the same potential, and the electrons and holes are transferred to the surface of the material at the same time. Under simulated solar light irradiation, both $\mathrm{BiOCl}$ and $\mathrm{ZnO}$ produce photogenerated electron-hole pairs, the photoexcited electrons in the conduction band (CB) of $\mathrm{BiOCl}$ are transferred to the conduction band of $\mathrm{ZnO}$ through the heterojunctional interface as the $\mathrm{CB}$ of $\mathrm{BiOCl}$ lies above the $\mathrm{CB}$ of $\mathrm{ZnO}$. Since the valance band $(\mathrm{VB})$ of $\mathrm{BiOCl}$ lies above the $\mathrm{VB}$ of $\mathrm{ZnO}$, the holes remain the in the $\mathrm{VB}$ of $\mathrm{BiOCl}$, which improves the separation efficiency of photogenerated electron-hole pairs to improve the photocatalytic degradation efficiency. These electrons in the $\mathrm{CB}$ of $\mathrm{ZnO}$ combine with adsorbed $\mathrm{O}_{2}$ molecules to form ${ }^{\bullet} \mathrm{O}_{2}{ }^{-}$, which are the major degrading species in the degradation of $\mathrm{TC}-\mathrm{HCl}$ by $\mathrm{Ag} @ \mathrm{ZnO} / \mathrm{BiOCl}$. The introduction of $\mathrm{Ag}$ induces surface plasmon resonance excited electrons to the $\mathrm{CB}$ of $\mathrm{ZnO}$ to further enhance the formation of ${ }^{-} \mathrm{O}_{2}{ }^{-}$and hence improves photocatalytic degradation. The excited holes in the VB of the $\mathrm{BiOCl}$ on the surface of $\mathrm{Ag}$ nanoparticles participate in the oxidation reaction. Thus, the introduction of Ag nanoparticles not only improve charge separation and light absorption of $\mathrm{Ag} @ \mathrm{ZnO} / \mathrm{BiOCl}$ nanocomposite, but also plays very important role in the degradation of $\mathrm{TC}-\mathrm{HCl}$ through surface catalysis.
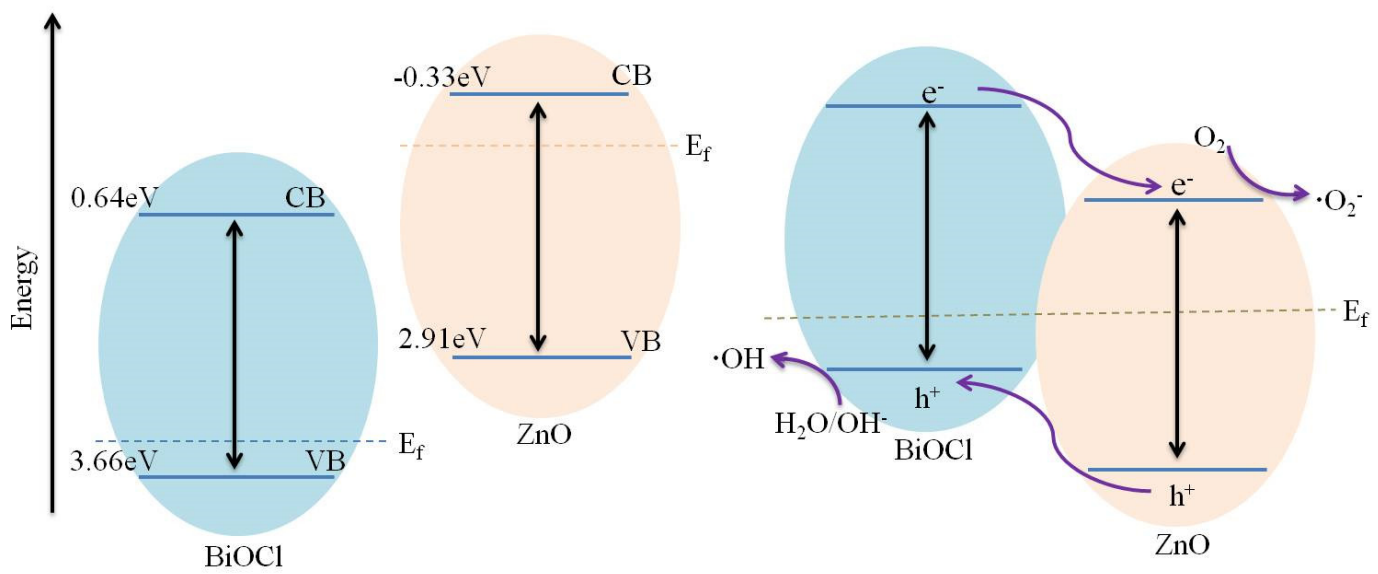

Figure 11. Ag@ZnO/BiOCl photocatalytic mechanism diagram.

\section{Conclusions}

In this work, $\mathrm{ZnO} / \mathrm{BiOCl}$ nanocomposites modified by $\mathrm{Ag}$ nanoparticles were prepared by in situ precipitation and hydrothermal synthesis. The samples were adequately characterized and applied for the photocatalytic degradation of tetracycline hydrochloride. After loading Ag nanoparticles, the visible light response range of $\mathrm{Ag} @ \mathrm{ZnO} / \mathrm{BiOCl}$ composite was extended, and its photocatalytic activity was enhanced. The improvement of the photocatalytic activity of $\mathrm{Ag} @ \mathrm{ZnO} / \mathrm{BiOCl}$ is due to the surface plasmon resonance effect and enhanced charge separation of Ag nanoparticles. The optimized sample, i.e., $4 \%$ $\mathrm{Ag} @ \mathrm{ZnO} / \mathrm{BiOCl}$ showed, respectively, 2.3 and 1.6 times enhanced degradation efficiency than $\mathrm{ZnO}$ and $\mathrm{ZnO} / \mathrm{BiOCl}$. The $\mathrm{Ag} @ \mathrm{ZnO} / \mathrm{BiOCl}$ catalyst has a good potential for the degradation of organic pollutants in water, considering the simplicity of the preparation process and utilization of visible light.

Author Contributions: Data curation, N.L., M.L. and D.J.; Formal analysis, N.C., Y.Y. and J.J.; Investigation, Z.Z.; Methodology, A.Z. and J.J.; Writing-original draft, N.L. and M.L.; Writingreview \& editing, S.L. All authors have read and agreed to the published version of the manuscript. 
Funding: This work was supported by Natural Science Foundation of Liaoning Province (2020-MS312), Scientific Research Project of Shenyang Medical College $(20191025,20174043)$ and Scientific Research Project for University Students of Shenyang Medical College (20209032).

Data Availability Statement: Not applicable.

Conflicts of Interest: The authors declare no conflict of interest.

\section{References}

1. Malesic-Eleftheriadou, N.; Evgenidou, E.N.; Kyzas, G.Z.; Bikiaris, D.N.; Lambropoulou, D.A. Removal of antibiotics in aqueous media by using new synthesized bio-based poly(ethylene terephthalate)- $\mathrm{TiO}_{2}$ photocatalysts. Chemosphere 2019, 234, 746-755. [CrossRef] [PubMed]

2. Fan, X.; Gao, J.; Li, W.; Huang, J.; Yu, G. Determination of 27 pharmaceuticals and personal care products (PPCPs) in water: The benefit of isotope dilution. Front. Environ. Sci. Eng. 2019, 14, 8. [CrossRef]

3. Dehghan, A.; Zarei, A.; Jaafari, J.; Shams, M.; Mousavi Khaneghah, A. Tetracycline removal from aqueous solutions using zeolitic imidazolate frameworks with different morphologies: A mathematical modeling. Chemosphere 2019, 217, 250-260. [CrossRef] [PubMed]

4. Li, W.; Zhuang, C.; Li, Y.; Gao, C.; Jiang, W.; Sun, Z.; Qi, K. Anchoring ultra-small TiO ${ }_{2}$ quantum dots onto ultra-thin and large-sized Mxene nanosheets for highly efficient photocatalytic water splitting. Ceram. Int. 2021, 47, 21769-21776. [CrossRef]

5. Yang, X.; Tian, J.; Guo, Y.; Teng, M.; Liu, H.; Li, T.; Lv, P.; Wang, X. ZnO Nano-Rod Arrays Synthesized with Exposed \{0001\} Facets and the Investigation of Photocatalytic Activity. Crystals 2021, 11, 522. [CrossRef]

6. Qi, K.; Zada, A.; Yang, Y.; Chen, Q.; Khataee, A. Design of 2D-2D NiO/g- $\mathrm{C}_{3} \mathrm{~N}_{4}$ heterojunction photocatalysts for degradation of an emerging pollutant. Res. Chem. Intermed. 2020, 46, 5281-5295. [CrossRef]

7. Zhang, H.; Li, Y.; Li, W.; Zhuang, C.; Gao, C.; Jiang, W.; Sun, W.; Qi, K.; Sun, Z.; Han, X. Designing large-sized cocatalysts for fast charge separation towards highly efficient visible-light-driven hydrogen evolution. Int. J. Hydrogen Energy 2021, 46, 28545-28553. [CrossRef]

8. Zada, A.; Khan, M.; Qureshi, M.N.; Liu, S.-y.; Wang, R. Accelerating Photocatalytic Hydrogen Production and Pollutant Degradation by Functionalizing $\mathrm{g}-\mathrm{C}_{3} \mathrm{~N}_{4}$ With $\mathrm{SnO}_{2}$. Front. Chem. 2020, 7, 941. [CrossRef]

9. Qi, K.; Cheng, B.; Yu, J.; Ho, W. A review on TiO 2 -based Z-scheme photocatalysts. Chin. J. Catal. 2017, 38, 1936-1955. [CrossRef]

10. Liu, S.-y.; Ru, J.; Liu, F. NiP/CuO composites: Electroless plating synthesis, antibiotic photodegradation and antibacterial properties. Chemosphere 2021, 267, 129220. [CrossRef]

11. Al Suliman, N.; Awada, C.; Alshoaibi, A.; Shaalan, N.M. Simple Preparation of Ceramic-Like Materials Based on 1D-Agx(x=0, 5, 10, 20, $40 \mathrm{mM}$ )/TiO2 Nanostructures and Their Photocatalysis Performance. Crystals 2020, 10, 1024. [CrossRef]

12. Li, C.; Wu, X.; Shan, J.; Liu, J.; Huang, X. Preparation, Characterization of Graphitic Carbon Nitride Photo-Catalytic Nanocomposites and Their Application in Wastewater Remediation: A Review. Crystals 2021, 11, 723. [CrossRef]

13. Zhu, Z.; Han, S.; Cao, Y.; Jiang, J. Synthesis of a Novel Photocatalyst $\mathrm{MVO}_{4} / \mathrm{g}_{-} \mathrm{C}_{3} \mathrm{~N}_{4}(\mathrm{M}=\mathrm{La}$, Gd) with Better Photocatalytic Activity for Tetracycline Hydrochloride Degradation under Visible-Light Irradiation. Crystals 2021, 11, 756. [CrossRef]

14. Jin, Y.; Xing, Z.; Li, Y.; Han, J.; Lorenz, H.; Chen, J. Synthetic BiOBr/Bi2S 3 /CdS Crystalline Material and Its Degradation of Dye under Visible Light. Crystals 2021, 11, 899. [CrossRef]

15. Qi, K.; Lv, W.; Khan, I.; Liu, S.-y. Photocatalytic $\mathrm{H}_{2}$ generation via CoP quantum-dot-modified g- $\mathrm{C}_{3} \mathrm{~N}_{4}$ synthesized by electroless plating. Chin. J. Catal. 2020, 41, 114-121. [CrossRef]

16. Ruqaishy, M.A.; Marzouqi, F.A.; Qi, K.; Liu, S.-Y.; Karthikeyan, S.; Kim, Y.; Al-Kindy, S.M.Z.; Kuvarega, A.T.; Selvaraj, R. Template-free preparation of $\mathrm{TiO}_{2}$ microspheres for the photocatalytic degradation of organic dyes. Korean J. Chem. Eng. 2018, 35, 2283-2289. [CrossRef]

17. He, W.; Wu, H.; Wamer, W.G.; Kim, H.-K.; Zheng, J.; Jia, H.; Zheng, Z.; Yin, J.-J. Unraveling the Enhanced Photocatalytic Activity and Phototoxicity of $\mathrm{ZnO} /$ Metal Hybrid Nanostructures from Generation of Reactive Oxygen Species and Charge Carriers. ACS Appl. Mater. Interfaces 2014, 6, 15527-15535. [CrossRef]

18. Praus, P.; Svoboda, L.; Dvorský, R.; Reli, M. Nanocomposites of $\mathrm{SnO}_{2}$ and g- $\mathrm{C}_{3} \mathrm{~N}_{4}$ : Preparation, characterization and photocatalysis under visible LED irradiation. Ceram. Int. 2018, 44, 3837-3846. [CrossRef]

19. Qi, K.; Liu, S.-y.; Zada, A. Graphitic carbon nitride, a polymer photocatalyst. J. Taiwan Inst. Chem. Eng. 2020, 109, 111-123. [CrossRef]

20. Wang, G.; Long, X.; Qi, K.; Dang, S.; Zhong, M.; Xiao, S.; Zhou, T. Two-dimensional CdS/g-C ${ }_{6} \mathrm{~N}_{6}$ heterostructure used for visible light photocatalysis. Appl. Surf. Sci. 2019, 471, 162-167. [CrossRef]

21. Zhao, K.; Khan, I.; Qi, K.; Liu, Y.; Khataee, A. Ionic liquid assisted preparation of phosphorus-doped g- $\mathrm{C}_{3} \mathrm{~N}_{4}$ photocatalyst for decomposition of emerging water pollutants. Mater. Chem. Phys. 2020, 253, 123322. [CrossRef]

22. Chang, S.; Sang, Y.; Liu, H. Efficient Photocatalytic Degradation of RhB by Constructing $\mathrm{Sn}_{3} \mathrm{O}_{4}$ Nanoflakes on Sulfur-Doped $\mathrm{NaTaO}_{3}$ Nanocubes. Crystals 2021, 11, 59. [CrossRef]

23. Wierzbicka, E.; Syrek, K.; Maczka, K.; Sulka, G.D. Photocatalytic Decolorization of Methyl Red on Nanoporous Anodic $\mathrm{ZrO}_{2}$ of Different Crystal Structures. Crystals 2021, 11, 215. [CrossRef] 
24. Alharthi, F.A.; Alanazi, H.S.; Alsyahi, A.A.; Ahmad, N. Hydrothermal Synthesis, Characterization and Exploration of Photocatalytic Activities of Polyoxometalate: $\mathrm{Ni}_{-\mathrm{CoWO}}$ Nanoparticles. Crystals 2021, 11, 456. [CrossRef]

25. Yang, Y.; Li, Y.; Zhu, L.; He, H.; Hu, L.; Huang, J.; Hu, F.; He, B.; Ye, Z. Shape control of colloidal Mn doped ZnO nanocrystals and their visible light photocatalytic properties. Nanoscale 2013, 5, 10461-10471. [CrossRef] [PubMed]

26. Miao, L.; Shi, B.; Stanislaw, N.; Mu, C.; Qi, K. Facile synthesis of hierarchical ZnO microstructures with enhanced photocatalytic activity. Mater. Sci.-Pol. 2017, 35, 45-49. [CrossRef]

27. Qi, K.; Cheng, B.; Yu, J.; Ho, W. Review on the improvement of the photocatalytic and antibacterial activities of ZnO. J. Alloys Compd. 2017, 727, 792-820. [CrossRef]

28. Liu, X.; Xu, H.; Li, D.; Zou, Z.; Xia, D. Facile Preparation of BiOCl/ZnO Heterostructure with Oxygen-Rich Vacancies and Its Enhanced Photocatalytic Performance. Chem. Sel. 2019, 4, 12245-12251. [CrossRef]

29. Qi, K.; Liu, S.-y.; Selvaraj, R.; Wang, W.; Yan, Z. Comparison of Pt and Ag as co-catalyst on g-C3N4 for improving photocatalytic activity: Experimental and DFT studies. Desalin. Water Treat. 2019, 153, 244-252. [CrossRef]

30. An, C.; Peng, S.; Sun, Y. Facile Synthesis of Sunlight-Driven AgCl:Ag Plasmonic Nanophotocatalyst. Adv. Mater. 2010, 22, 2570-2574. [CrossRef]

31. Zhang, S.; Khan, I.; Qin, X.; Qi, K.; Liu, Y.; Bai, S. Construction of 1D Ag-AgBr/AlOOH Plasmonic Photocatalyst for Degradation of Tetracycline Hydrochloride. Front. Chem. 2020, 8, 117. [CrossRef]

32. Boltersdorf, J.; Leff, A.C.; Forcherio, G.T.; Baker, D.R. Plasmonic Au-Pd Bimetallic Nanocatalysts for Hot-Carrier-Enhanced Photocatalytic and Electrochemical Ethanol Oxidation. Crystals 2021, 11, 226. [CrossRef]

33. Zada, A.; Muhammad, P.; Ahmad, W.; Hussain, Z.; Ali, S.; Khan, M.; Khan, Q.; Maqbool, M. Surface Plasmonic-Assisted Photocatalysis and Optoelectronic Devices with Noble Metal Nanocrystals: Design, Synthesis, and Applications. Adv. Funct. Mater. 2019, 30, 1906744. [CrossRef]

34. Christopher, P.; Ingram, D.B.; Linic, S. Enhancing Photochemical Activity of Semiconductor Nanoparticles with Optically Active Ag Nanostructures: Photochemistry Mediated by Ag Surface Plasmons. J. Phys. Chem. C 2010, 114, 9173-9177. [CrossRef]

35. Ren, C.; Yang, B.; Wu, M.; Xu, J.; Fu, Z.; Lv, Y.; Guo, T.; Zhao, Y.; Zhu, C. Synthesis of Ag/ZnO nanorods array with enhanced photocatalytic performance. J. Hazard. Mater. 2010, 182, 123-129. [CrossRef]

36. Rupa, A.V.; Manikandan, D.; Divakar, D.; Sivakumar, T. Effect of deposition of $\mathrm{Ag}$ on $\mathrm{TiO}_{2}$ nanoparticles on the photodegradation of Reactive Yellow-17. J. Hazard. Mater. 2007, 147, 906-913. [CrossRef] [PubMed]

37. Qi, K.; Xing, X.; Zada, A.; Li, M.; Wang, Q.; Liu, S.-Y.; Lin, H.; Wang, G. Transition metal doped ZnO nanoparticles with enhanced photocatalytic and antibacterial performances: Experimental and DFT studies. Ceram. Int. 2020, 46, 1494-1502. [CrossRef]

38. He, G.; Xing, C.; Xiao, X.; Hu, R.; Zuo, X.; Nan, J. Facile synthesis of flower-like $\mathrm{Bi}_{12} \mathrm{O}_{17} \mathrm{Cl}_{2} / \beta-\mathrm{Bi}_{2} \mathrm{O}_{3}$ composites with enhanced visible light photocatalytic performance for the degradation of 4-tert-butylphenol. Appl. Catal. B Environ. 2015, 170, 1-9. [CrossRef]

39. Kong, L.; Yu, B.; Xu, X.; Pan, J.; Su, Y.; Hu, J. Room Temperature Ferromagnetism and Photoluminescence in Cu-Doped ZnO Nanocrystals. J. Nanosci. Nanotechnol. 2014, 14, 6012-6015. [CrossRef] [PubMed]

40. Jiang, D.; Wang, T.; Xu, Q.; Li, D.; Meng, S.; Chen, M. Perovskite oxide ultrathin nanosheets/g-C $\mathrm{C}_{3} \mathrm{~N}_{4} 2 \mathrm{D}-2 \mathrm{D}$ heterojunction photocatalysts with significantly enhanced photocatalytic activity towards the photodegradation of tetracycline. Appl. Catal. $B$ Environ. 2017, 201, 617-628. [CrossRef] 